\title{
Feature and Tendency of Technology Transfer in Z-Park Patent Cooperation Network: From the Perspective of Global Optimal Path
}

\author{
Jun Guan, Jingying Xu, Yu Han, Dawei Wang, Lizhi Xing ${ }^{\dagger}$
}

School of Economics and Management, Beijing University of Technology, Beijing 100124, China

\begin{abstract}
Purpose: This study aims to provide a new framework for analyzing the path of technology diffusion in the innovation network at the regional level and industrial level respectively, which is conducive to the integration of innovation resources, the coordinated development of innovative subjects, and the improvement of innovation abilities.
\end{abstract}

Design/methodology/approach: Based on the Z-Park patent cooperation data, we establish Inter-Enterprise Technology Transfer Network model and apply the concept of Pivotability to describe the key links of technology diffusion and quantify the importance of innovative partnerships. By measuring the topologically structural characteristics in the levels of branch park and the technosphere, this paper demonstrates how technology spreads and promotes overall innovation activities within the innovation network.

Findings: The results indicate that: (1) Patent cooperation network of the Z-Park displays heterogeneity and the connections between the innovative subjects distribute extremely uneven. (2) Haidian park owns the highest pivotability in the IETTN model, yet the related inter-enterprise patent cooperation is mainly concentrated in its internal, failing to facilitate the technology diffusion across multiple branch parks. (3) Such fields as "electronics and information" and "advanced manufacturing" are prominent in the cross-technosphere cooperation, while fields such as "new energy" and "environmental protection technology" can better promote industrial integration.

Research limitations: Only the part of the joint patent application is taken into account while establishing the patent cooperation network. The other factors that influence the mechanism of technology diffusion in the innovation network need to be further studied, such as financial capital, market competition, and personnel mobility, etc.

Practical implications: The findings of this paper will provide useful information and suggestions for the administration and policy-making of high-tech parks.

\footnotetext{
Correspondence author: Lizhi Xing (Email: itwasa@163.com).
}

Citation: Guan, J., Xu, J.Y., Han, Y., Wang, D.W., \& Xing, L.Z. (2021).

Feature and tendency of technology transfer in Z-Park patent cooperation network: From the Perspective of Global Optimal Path. Journal of Data and Information Science, 6(4), 111-138. https://doi. org/10.2478/jdis-20210034

Received: Jan. 23, 2021

Revised: Mar. 11, 2021

Accepted: Mar. 29, 2021 


\section{Research Paper}

Originality/value: The value of this paper is to build a bridge between the massive amount of patent data and the nature of technology diffusion, and to develop a set of tools to analyze the nonlinear relations between innovative subjects.

Keywords Patent Cooperation; Innovation Network; Industrial Integration; Z-Park

\section{Introduction}

With the rapid development of the global economy and on-going factor reallocation, modern society is now becoming a knowledge society that takes knowledge production and utilization as its core resources (Mao et al., 2020). Innovation has become the basis for the sustainable development of enterprises and the improvement of global competitiveness. The study of the innovation paradigm in western economics and management has gone through three stages (Laranja, Uyarra, \& Flanagan, 2008). Joseph Alois Schumpeter was the pioneer of innovation theory. He pointed out that innovation is the creation of a new production function, that is, the creation of a new product or the creation of new characteristics of an existing product through a new combination of factors of production (Schumpeter, 1911). Since the 1970s, with the development of technology and industry, innovation is not only the independent behavior of a single individual but also the correlation between innovation subjects. Drucker divided innovation into two categories. One is technological innovation, that is, to make new use of certain natural objects and endow them with new economic value. The other is social innovation, creating new management methods and management institutions in the society to obtain more economic and social values through resource allocation (Drucker, 1985). Freeman first put forward the concept of "the national innovation system" when he studied the technology policy and economic performance of Japan (Freeman, 1987). Lundvall believes that the core of the national innovation system is the learning activity of the interaction between producers and users (Lundvall, 1992). To reduce costs and improve efficiency, more and more companies are gradually adjusting their innovation strategies to develop partnerships with others (Wei et al., 2019). Relationships between innovative enterprises include formal ones featuring stable cooperation and informal exchanges and contacts (Lu et al., 2019). Now the research on the concept of innovation has entered the third stage. Since the mid-1990s, niche research has been introduced into the research of technological capability and technological innovation. As an intuitive abstraction of the complex system, the network structure fully embodies the intricate relationship between various entities and explains the dynamic mechanism. Network theory also provides explanations for a myriad of social phenomena, from individual creativity to corporate profitability (Stephen et al., 2009).

Journal of Data and

The research on innovation networks was first proposed by American sociologist Information Science Burt (1983), who first recognized the significant impact of social networks on 
Feature and Tendency of Technology Transfer in Z-Park Patent Cooperation Network:

From the Perspective of Global Optimal Path

Jun Guan et al.

technological innovation. His research put forward that the foundation of the innovation network topology lies in the innovation cooperation links between enterprises, and classified those links (Freeman, 1995). Based on the in-depth research, the innovation network is classified, such as enterprises and R\&D companies, technology exchange agreements, cooperative R\&D agreements, license agreements, subcontracting, and production divisions (Freeman, 1991). Rosalba, Rebeca, and Josefa (2000) pointed out that the innovation network can be used to analyze how enterprises can improve the management level, scientific research ability, and optimize market positioning through cooperation agreements, subcontracting agreements, management contracts, research and development cooperation, and product sharing. From the perspective of the formation of innovation network, DeBresson and Amesse (1991) believed that three main factors are affecting the innovation network, one is the uncertainty of technology and market, the other two are the complexity of technology and the additional benefits generated after the success of technical cooperation. Collaborative characteristics of the network were emphasized, that is, the overall innovation capability of the network far exceeds the sum of the innovation capabilities of every individual enterprise (Sternberg \& Arndt, 2000). Enterprises can obtain the required innovation resources through the innovation network to overcome the shortage of their resources (Musiolik, Markard, \& Hekkert, 2012). Hienerth, Lettl, and Keinz (2014) emphasized the synergies of innovation networks, which can effectively reduce the risks of innovative enterprises, expand the design space of the company's products and make the user enterprises no longer have to rush to choose the appropriate products. Many experts and scholars have conducted empirical research on the mechanism of the innovation networks. As the basic elements of mutual communication and cooperation, network nodes will gradually strengthen the relationship between each other in the long-term interaction and cooperation. Meanwhile, the attraction and cohesion of network organizations should be continuously improved (Tang, Ma, \& Xi, 2004). Lee, Park, and Yoon found that an open network plays a positive role in improving the innovation potential of small and medium-sized enterprises in South Korea. The formation of an innovation network is conducive to the transformation and upgrading of regional industrial clusters. Rampersad, Quester, and Troshani (2010) pointed out that innovation network structure has a great influence on product development and innovation management. Enterprises can obtain the required innovation resources through the innovation network to overcome the deficiency of their resources. Chai et al. (2020) indicate that out-degree centrality and network constraint have a significantly positive effect on green patent value through the study of the lightemitting diode industry. Cong, Zou, and Wu (2017) show that the embedded relationships, embedded structures, and embedded resources in the organizational network can effectively improve the knowledge management ability of the firm

Journal of Data and Information Science

http://www.jdis.org https://www.degruyter:com/view/j/jdis 


\section{Research Paper}

and significantly improve the performance of the firm's technological innovation. In terms of analyzing the innovation network structure, Foss, Lyngsie, and Zahra (2013) proposed that innovative enterprises, partners, competitors, intermediaries, research institutes, universities, industry associations, and governments constitute innovation networks. Overall and individual structural characteristics of the network affect cluster innovation and enterprise innovation (Zhou, 2010). The limited and uneven distribution of network resources will therefore increase the risk of innovation (Xue \& Dang, 2004). In his research, Maroulis (2017) found that enterprises in the center of network or structure hole can have more resource advantages than those on the edge of knowledge acquisition and transmission. Liu, Zhang, and Cao (2017) have studied that, compared with degree centrality and closeness centrality, the betweenness centrality of existing nodes can better predict preferential attachment. Hung and Wang (2010) found most patent citation activities have relations with the patents of high betweenness centrality. Shi et al. (2020) found that enterprises with high network inertia in innovative networks are less likely to seek resources beyond their boundaries by studying patent data collected by the smartphone industry from 2000 to 2017. Hua and Wang (2015) studied the effect of network structure on innovation efficiency by establishing the simulation model of the innovation process under the environment of innovation networks. Based on the data of High-tech enterprises in China, Fang et al. (2019) studied the effect of two types of network capability, namely network structure capability and network relationship capability on the innovation performance by multiple hierarchical regression method.

Originating from the "Zhongguancun Electronic Street" in the 1980s, Z-Park is China's first national innovation demonstration zone. After more than 30 years of development, Z-Park has developed into an innovation cluster with sixteen parks (Chen, Wu, \& Liu, 2014). Touted as China's Silicon Valley (Tzeng, 2010), Z-Park is the fountainhead of China's technological innovation and the first pilot area in terms of institutional innovation, responsible for leading the strategic leapfrog of China's emerging industries (Jiang et al., 2016). The figure below (Figure 1) shows the locations and scales of sixteen parks in Z-Park, in which the yellow area is Z-Park, and the gray map is the administrative division map of Beijing. The table at the bottom right of the picture shows the occupied area by each park.

In conclusion, existing studies have confirmed the importance of key innovation nodes to the innovation network, but most of them are qualitative descriptions or relationship analyses between the node's network location and innovation performance. Most of them emphasize the nodes' effect on the innovation network, with little consideration of the cooperation networks. And in lack of high-dimensional data, the geographical and industrial influence on technology diffusion is usually ignored and regarded as tacit knowledge. In this paper, we proposed a networkbased framework that detects the relevance among innovative partners by analyzing the regional and industrial characteristics of the network connecting edges. Their 
Feature and Tendency of Technology Transfer in Z-Park Patent Cooperation Network:

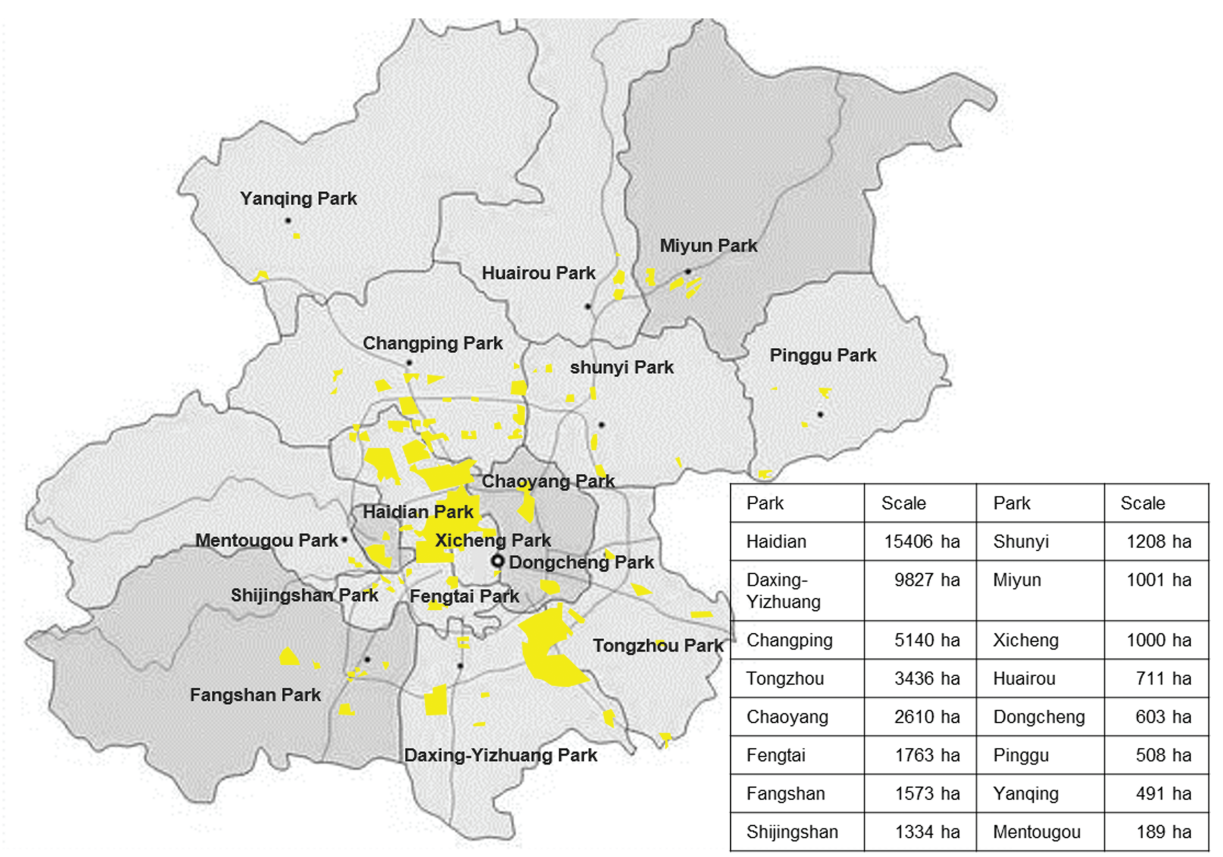

Figure 1. Map of 16 parks in Z-Park. Source: http://zgcgw.beijing.gov.cn/

network-based features (the so-called structure variables), brought by the topological structure of the whole system, can be used to build a bridge between the microscopic structure characteristics and the synthetically macroscopic performance. We took the overall structure of the innovation network and the inter-enterprise innovation association based on technical cooperation, as the departure point to dig the innovative partnerships. This paper uses the patent cooperation data of high-tech enterprises in the Z-Park from 2008 to 2017 and establishes the Inter-Enterprise Technology Transfer Network (IETTN) to analyze the collaborative cooperation relationship between high-tech enterprises during the diffusion of emerging technology and how the region and industrial influence the diffusion process. By studying the influence of regions and industries on technology diffusion in the network, this article describes the status quo of regional cooperation and industry integration, analyzing the role of these attributes in promoting innovation cooperation.

\section{Methodology}

Through the establishment of the Inter-Enterprise Technology Transfer Network (IETTN), this paper quantifies the communication of enterprises in technological innovation and analyzes the role of enterprises in the innovation network.

Journal of Data and Information Science

http://www.jdis.org https://www.degruyter.com/view/j/jdis 


\section{Research Paper}

\subsection{Inter-Enterprise Technology Transfer Network (IETTN)}

A patent is an important carrier of enterprise technology innovation, and patent cooperation among enterprises promotes technology diffusion and sharing in the region. Patents are an up-to-date and reliable knowledge source of innovative technologies, and therefore patent analysis has been a vital tool for understanding technological trends and formulating technology strategies (Yoon \& Kim, 2012). Based on previous studies, patent cooperation among enterprises can fall into three types: joint application, patent transfer, and patent licensing. The frequency of patent cooperation reflects the level of innovation cooperation between enterprises. This article uses the IETTN model to study the strong correlation in patent cooperation, based on the joint patent application data provided by Z-Park Management Committee. The list of enterprises includes state-owned enterprises, branches, subsidiaries, research institutions, and other innovative entities that registered with the State Administration for Industry and Commerce. The following figure shows the number of innovation entities and innovation cooperation in the IETTN model from 2008 to 2017, as well as the regional innovation performance indicators (including gross industrial output value and technical income) of Z-Park. The left axis corresponds to the number of enterprises inside and outside Z-Park, while the right axis shows the number of cooperative patent applications, gross

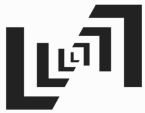

Journal of Data and Information Science

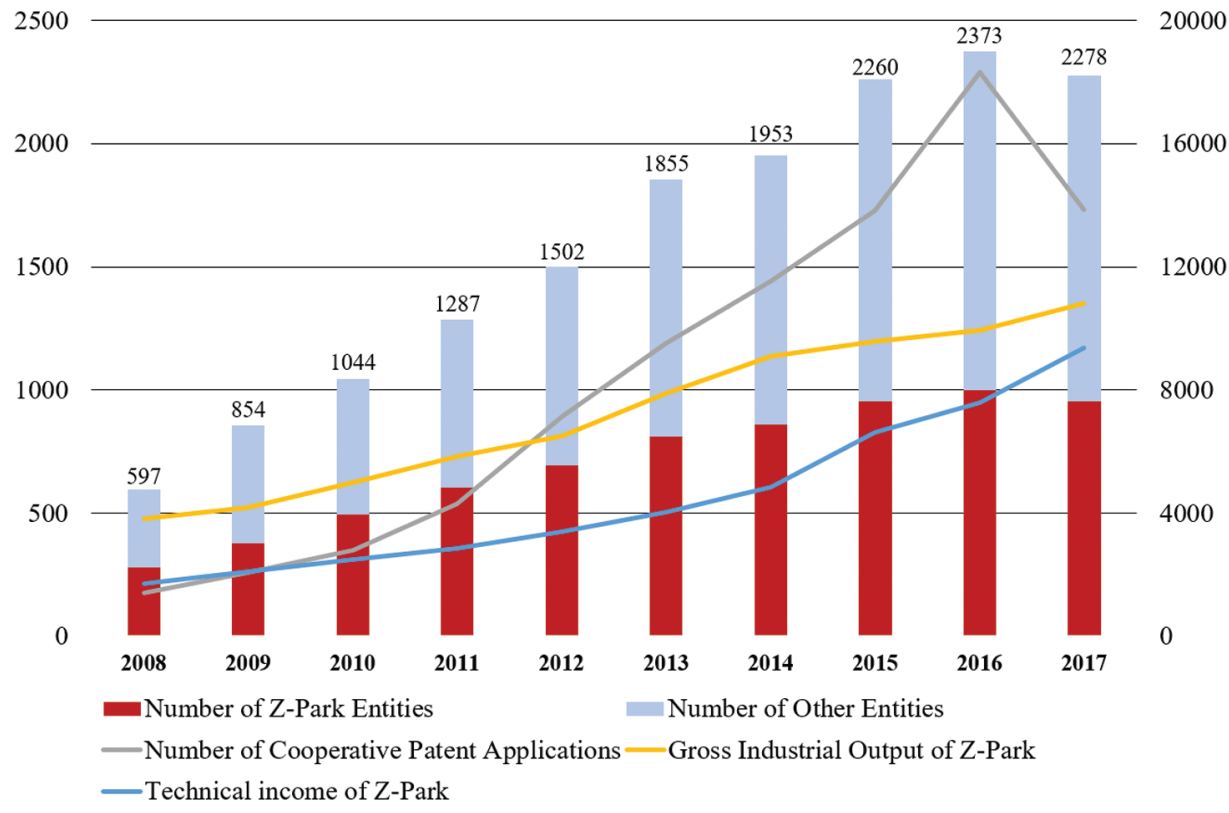

Figure 2. Data statistics and innovation performance. 
Feature and Tendency of Technology Transfer in Z-Park Patent Cooperation Network:

industrial output, and technical income. It can be shown that more and more entities join the innovation cooperation and the number of innovation cooperation is on the rise while the regional innovative capacity is also continuously strengthened.

Because of the replicability of technology, the technology flow in the regional innovation network has a strong externality. We employed the co-citation modeling method in (Lin et al., 2020) to transform the direct relationship of patent-enterprise to the undirected enterprise-to-enterprise innovation cooperation to study technology diffusion between high-tech enterprises, in which the joint application strength of enterprises $i$ and $j(i \neq j)$ is as follows:

$$
C_{i j}=\sum_{k=1}^{N} a_{k i} a_{k j}
$$

Where the node $k$ represents a patent applied jointly by enterprises $i$ and $j$, so the patent $k$ has two in-edges coming from enterprises $i$ and $j$ and $a_{k i} a_{k j}=1$, otherwise $a_{k i} a_{k j}=0$. Considering the inter-enterprise patent cooperation studied in this paper, the number of patents independently applied by enterprises is excluded, so the diagonal elements are specified as zero in this paper. In this way, we build a weighted undirected network model in which nodes represent enterprises and edges represent joint application relationship, whose weight means the frequency of cooperation between enterprises. The higher the edge weight between the two nodes means that the two enterprises carry out frequent patent cooperation and establish a close communication relationship in terms of technology.

The Z-Park's IETTN model of the years 2008, 2011, 2014, and 2017 are shown in this section (Figure 3). The following graphs show innovation cooperation involving enterprises in Z-Park of the four years. The size and color of the nodes in the figure are related to the degree value, while the thickness of the edges reflects the frequency of patent cooperation. Also, the number on the node represents different enterprises. It can be seen that the number of nodes and edges in the network increased significantly from 2008 to 2017. This indicates that thanks to the support of innovation policies and increased innovation awareness, enhancement is seen not only in the innovation capability of high-tech enterprises but also in the technical communication and exchanges between them, which produces stronger externalities for regional technological and economic development. Besides, the difference of degree value between nodes in the network is becoming more significant. In the IETTN network of 2017, No. 123 (State Grid Corporation of China) is the most significant node in the network, and No. 70 (China Electric Power Research Institute) followed.

Z-Park falls into sixteen parks geographically and the high-tech enterprises in Z-Park are divided into 11 technospheres according to the Administrative Measures

Journal of Data and Information Science

http://www.jdis.org https://www.degruyter:com/view/j/jdis 


\section{Research Paper}

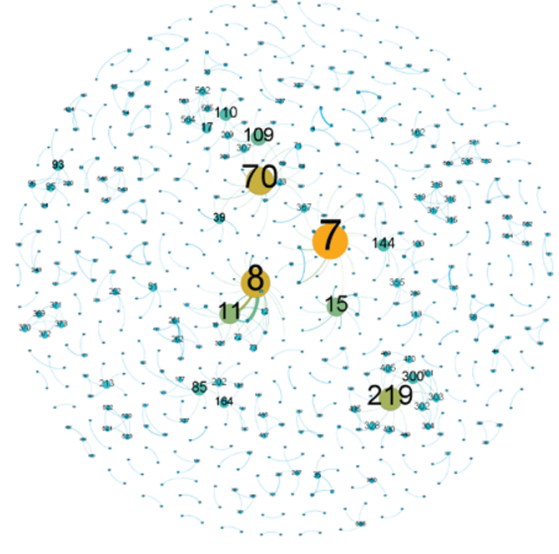

(a) 2008

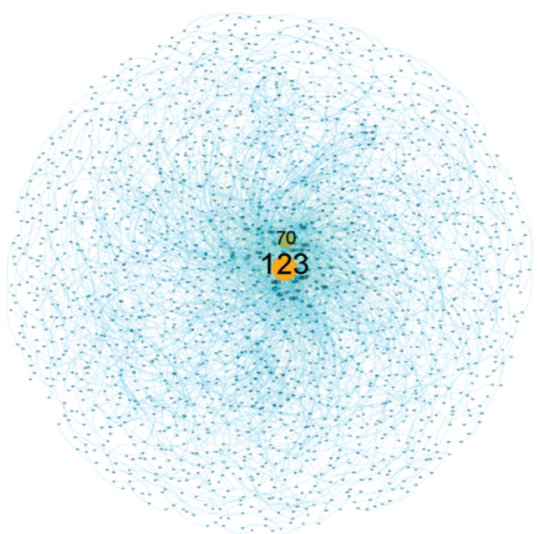

(c) 2014

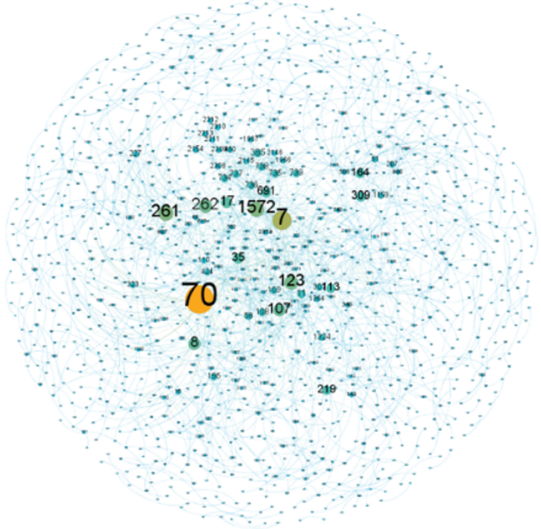

(b) 2011

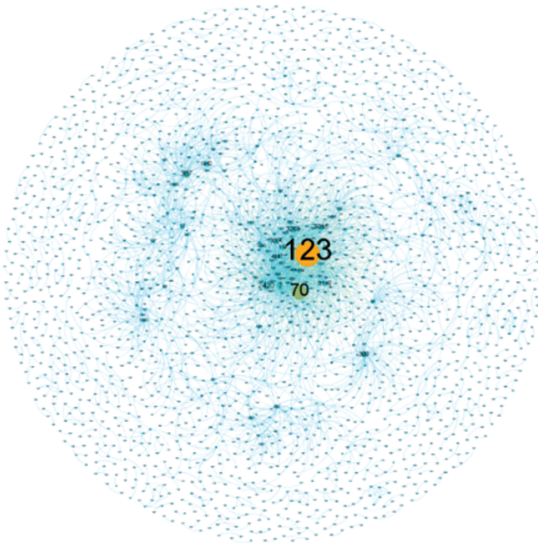

(d) 2017

Figure 3. IETTN-2008, 2011, 2014, and 2017.

【ัเง

Journal of Data and Information Science

for the Determination of Beijing High-tech Enterprises (specific classification are shown in Appendix I). To reflect the cooperation between parks and technospheres from 2008 to 2017, we established the IETTN-PA model (Figure 4) and the IETTN-TH model (Figure 5). In these figures, nodes represent different parks and technospheres within Z-Park, marked with the names of them. The thickness of the edges represents the frequency of cooperation. It should be noted that the colors of the nodes and edges have no special meaning, but just to distinguish the four years. 
Feature and Tendency of Technology Transfer in Z-Park Patent Cooperation Network: From the Perspective of Global Optimal Path

Jun Guan et al.

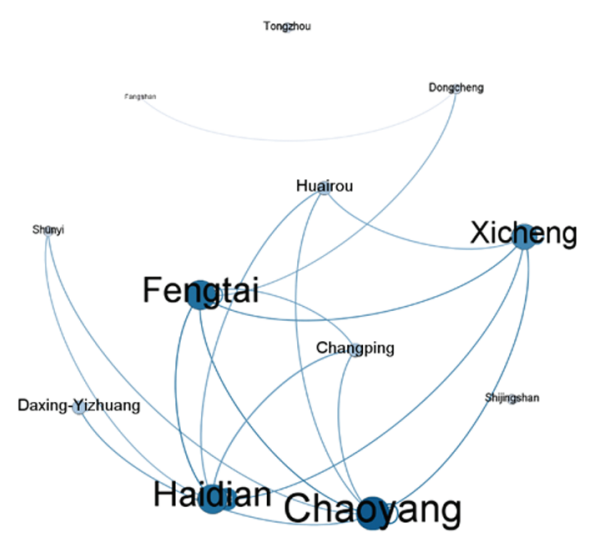

(a) 2008

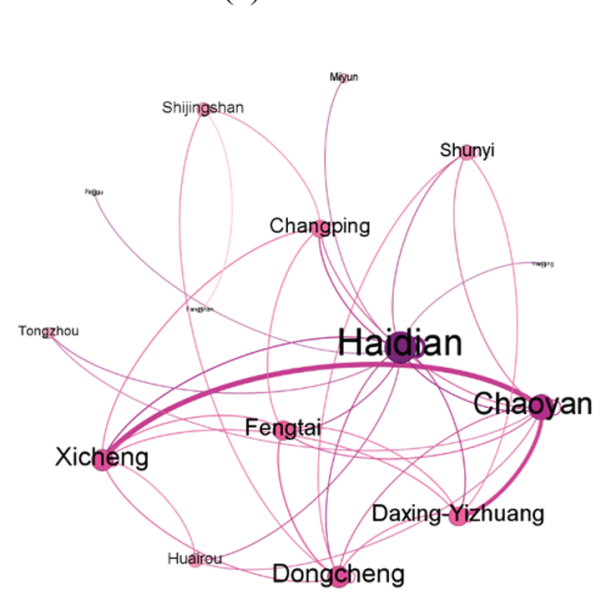

(c) 2014

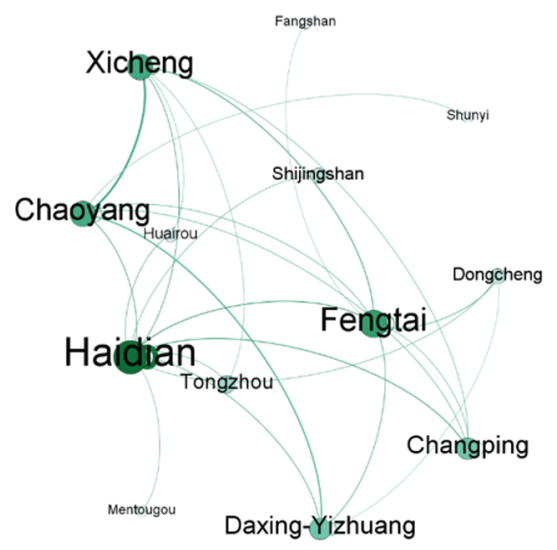

(b) 2011

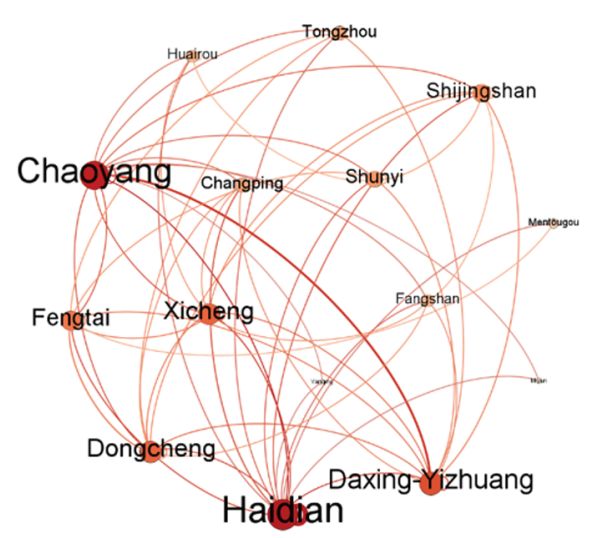

(d) 2017

Research Paper

Figure 4. IETTN-PA of four years.

It is also obvious from the above two figures that the cooperation across the park and the technosphere have been on the rise from 2008 to 2017, and the network has become denser. With cross-park and cross-technosphere patent cooperation being deepened, innovation diffusion is getting rid of regional and industrial barriers and continuously enhances integration and exchanges. When different regions and industries communicate and cooperate in technology, enterprises will constantly enrich their innovation resources, upgrade their innovation capabilities, and easily produce radical innovation. Although we have the patent data from 2008 to 2017.

Journal of Data and Information Science http://www.jdis.org https://www.degruyter:com/view/j/jdis 


\section{Research Paper}

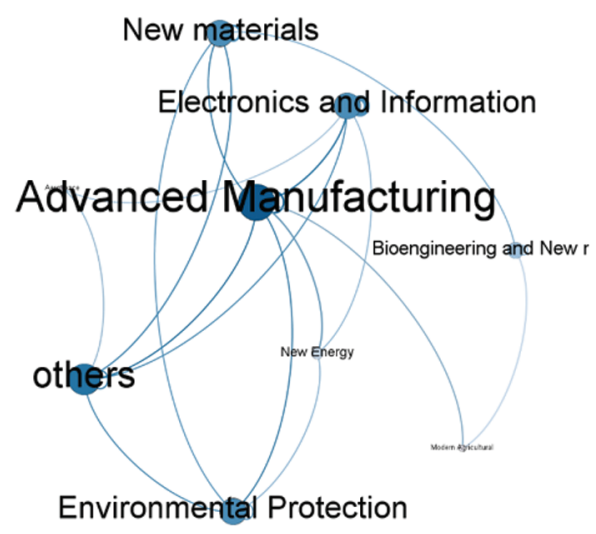

(a) 2008

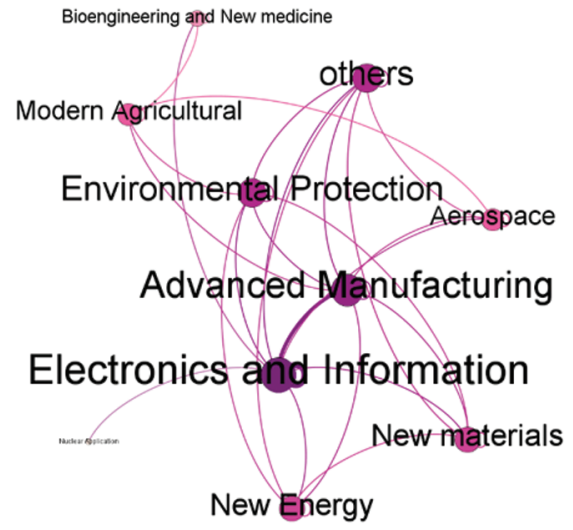

(c) 2014

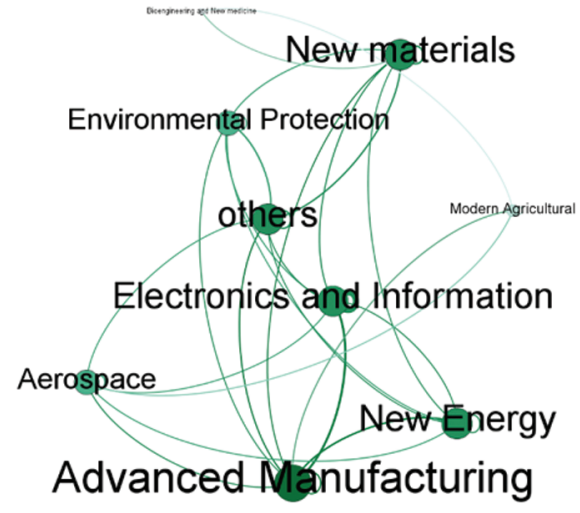

(b) 2011

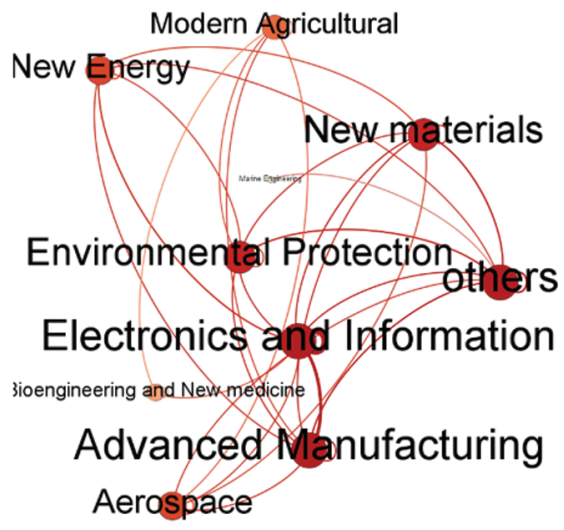

(d) 2017

Figure 5. IETTN-TH of four years.

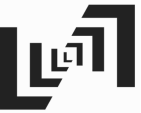

Journal of Data and Information Science
Due to the layout limitation and the clarity of the figure, we draw the figure above to demonstrate the degree distribution and log-log distribution of IETTN for four years. As the legend shows, nodes with different shapes represent different years. As can be seen from Figure 6, the heterogeneity of the network topology structure is significant in these four years, which means that a few enterprises have a lot of patent collaboration in the network while the majority of enterprises have relatively sparse collaborations. 
Feature and Tendency of Technology Transfer in Z-Park Patent Cooperation Network: From the Perspective of Global Optimal Path

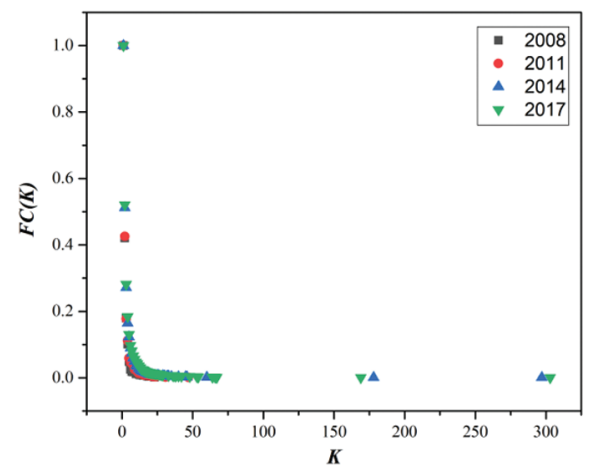

(a) Distribution of $K$

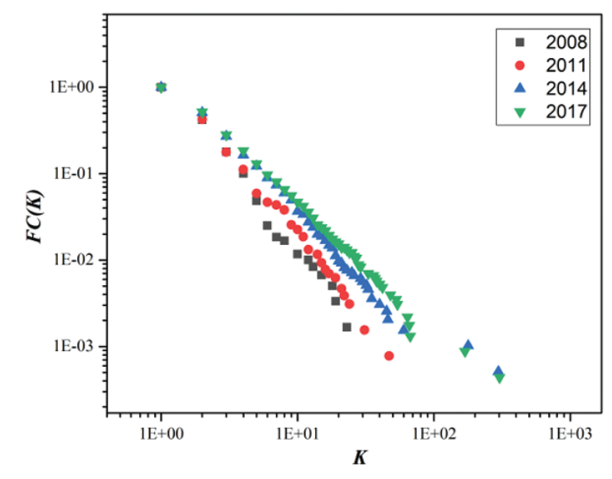

(b) Log-log Distribution of $K$

Figure 6. Distribution and log-log distribution of K in IETTN.

\subsection{Technology diffusion in IETTN model}

The IETTN model is an undirected but weighted network that takes innovation entities as nodes, and the number of times they cooperate on the application for patent as the weight of edges. The weighting of innovation associations can provide a more detailed description of the interaction structure of enterprises in the innovation network, and the intensity of innovation cooperation between the enterprises will have an important impact on the nature of the innovation network. Studies have shown that the distribution of weights can affect the structure and dynamic behavior of the network. Changes in weights can not only reduce the shortest distance in the network and increase the aggregation coefficient, endowing the network with the small-world effect, but also improve the synchronization ability of the network and affect the cluster structure of the network (Tian, Di, \& Yao, 2011).

Our research, therefore, is focused on the nature of weighted networks. According to the different meanings and ways of weighting, weights can be divided into two categories: dissimilarity weight and similarity weight. Similarity weights are commonly seen in social networks. Due to the difference in the fundamental nature of these two types of weights, definitions of the basic statistics for networks with dissimilarity weight and similarity weight are vastly different. From the perspective of the attribute of edge weight, the IETTN model is a typical network of similarity weights. The greater the edge weight of the network, the higher the frequency of patent application cooperation between enterprises. This also means that a closer innovation partnership has been forged between two entities.

Some corresponding concepts have been developed to characterize the structural properties of weighted networks, such as weights and their distribution characteristics,

Journal of Data and Information Science

http://www.jdis.org https://www.degruyter:com/view/j/jdis 


\section{Research Paper}

the correlation of weights, the shortest distance, the betweennesses values, and the definition and statistical properties of the aggregation degree on weighted networks, etc. (Wu \& Di, 2004). However, most of the indicators are commonly used to characterize the global and local structural properties of networks with dissimilarity weights, resulting in the partial loss of network information. As a result, it is necessary to introduce new geometric quantities to more accurately depict the nature of similarity weight networks from a global perspective based on the inheritance of the accuracy of original indicators.

In this paper, we utilize the Revised Floyd-Warshall Algorithm (RFWA) and Strongest Relevance Path Length (SRPL) (Xing et al., 2019) as the synthetic measurement of technology diffusion. This algorithm was first proposed by Xing and used to solve this operational problem of tracking network flow. Its iterative and convergence algorithm is as follows:

$$
S R P L_{i j}^{(k)}=\max _{i, j, k \in\{1,2, \ldots, N\}}\left\{w_{i j}^{(k-1)}, \frac{w_{i k}^{(k-1)} w_{k j}^{(k-1)}}{w_{i k}^{(k-1)}+w_{k j}^{(k-1)}}\right\}
$$

where $S R P L_{i j}^{(k)}$ is the SRPL between nodes $i$ and $j$, representing the propagation path with maximum efficiency and effectiveness. If it is greater than $w_{i j}^{(k-1)}$, we keep the record as it is, otherwise just equalize it to $w_{i j}^{(k-1)}$. When the $S R P L_{i j}^{(k)}$ happens to be equal to $w_{i j}^{(k-1)}$, it means the optimal path is just the most direct one between nodes $i$ and $j$. In the IETTN, $S R P L_{i j}^{(k)}$ is the most efficient path of technology diffusion between enterprises $i$ and $j$, providing a tool to measure the effectiveness of technical cooperation and exchange between enterprises through patent cooperation.

We abstract two sorts of matrixes from any given similarity-weight network based on SRPL, in which $S R P L^{\prime}$ is a numerical matrix, and $S R P L^{\prime \prime}$ is a string matrix:

$$
\begin{gathered}
S R P L^{\prime}=\left(\begin{array}{ccc}
S R P L_{11}^{(N)} & \cdots & S R P L_{1 N}^{(N)} \\
\vdots & \ddots & \vdots \\
S R P L_{N 1}^{(N)} & \cdots & S R P L_{N N}^{(N)}
\end{array}\right) \\
S R P L^{\prime \prime}=\left(\begin{array}{ccc}
S t r_{11}^{(N)} & \ldots & S t r_{1 N}^{(N)} \\
\vdots & \ddots & \vdots \\
S t r_{N 1}^{(N)} & \cdots & S t r_{N N}^{(N)}
\end{array}\right)
\end{gathered}
$$

Where $S R P L_{i j}^{(N)}$ is the value of the SRPL path between nodes $i$ and $j$ after global searching, and $S t r_{i j}^{(N)}$ embodies the concrete details of this path in sequence by a string, which begins from the very first character with the name of node $i$ and ends Information Science with the very last character with the name of node $j$. 
Feature and Tendency of Technology Transfer in Z-Park Patent Cooperation Network:

From the Perspective of Global Optimal Path

Jun Guan et al.

In the IETTN model, technology diffusion hides in numerous innovation cooperation and needs to be revealed according to the trade-off between the propagation efficiency and effectiveness of information flow. Therefore, SRPL is used to describe this process, and a brand-new network-based indicator will be designed as an analytical tool.

\subsection{Betweenness Centrality of Edge}

Newman generalized Freeman's betweenness centrality to edges and defined the Betweenness Centrality of Edge as the number of shortest paths between pairs of nodes that run along with it (Girvan \& Newman, 2002), namely:

$$
C_{E}(i, j)=\sum_{h, i, j, k \in\{1,2, \cdots, N\}} \frac{d_{h k}(i, j)}{d_{h k}}(i \neq j h \neq k)
$$

where $d_{h k}(i, j)$ is the number of the shortest paths connecting nodes $h$ and $k$ through $e(i, j)$, and $d_{h k}$ is the total number of the shortest paths connecting nodes $h$ and $k$.

To find the most important inter-park and inter-technosphere relations among numerous couples of sectors in IETTN models, weighted betweenness centrality of edge-based on RFWA is derived to measure the pivotability of patent-based relationships:

$$
C_{E}^{R F W A}(i, j)=\sum_{h, i, j, k \in\{1,2, \cdots, N\}} \operatorname{Str}_{h k}^{(N)}(i, j)
$$

where $S t r_{h k}^{(N)}$ is the number of SRPLs within the scope of the whole network, which is connecting any pairs of others cross a given couple of enterprises $i$ and $j$. Selfloop serving as an SRPL will plus 1 to this index of itself.

The following example is to explain how we pick an inter-node SRPL from various existing paths and then calculate the $C_{E}^{R F W A}$.

First of all, we need to know how many SRPL paths exist between any pair of nodes or on every single edge. In the network, as shown in Figure 7(a), we finally find out 8 SRPL paths and mark them with red dashed lines, which incorporate 7 direct paths and 1 indirect path. Except for the path of $A \rightarrow C$, the other edges are passed through by at least 1 SRPL path and at most 3 SRPL paths. Then, we can get the matrix of $C_{E}^{R F W A}$ based on the statistics on the SRPL paths. For instance, in Figure $7(\mathrm{~b}), C_{E}^{R F W A}(D, C)=3$ means 3 SRPL paths are passing through it. We will find an interesting pattern that the edge weight equals its corresponding SRPL value while its betweenness centrality exists.

Besides, it is worth testify whether there is a correlation between the weight of the edge and the $C_{E}^{R F W A}$. The truth is neither the edges with large weight nor the ones with small weight will certainly get a proportional $C_{E}^{R F W A}$, as shown in Figure 7(c). Based on the theory of "The Strength of Weak Ties" introduced by Granovetter

Journal of Data and Information Science

http://www.jdis.org https://www.degruyter.com/view/j/jdis 


\section{Research Paper}

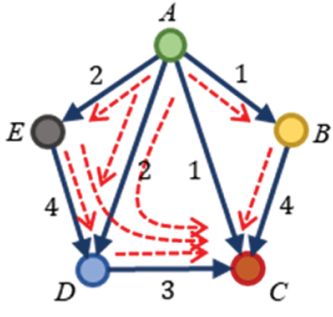

(a) SRPL Paths in the Network

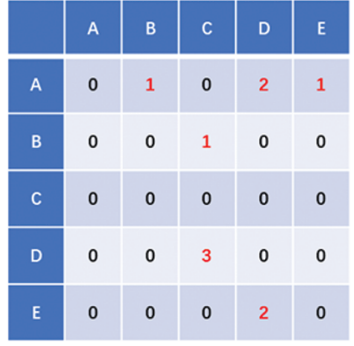

(b) Matrix of Betweenness Centrality of Edge

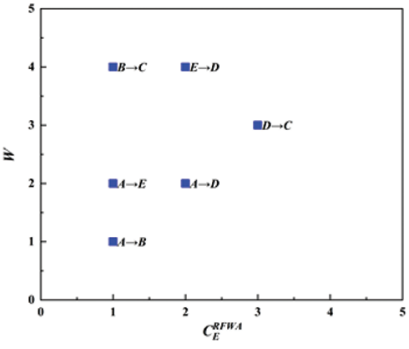

(c) Correlation between Weight and Betweenness Centrality of Edge

Figure 7. Weighted betweenness centrality of edge based on RFWA in similarity-weight network.

(1973), we recognize that a weak tie connecting two heterogeneous communities will have a large betweenness centrality because it plays a crucial role in information bridge. If the background is set to a similarity-weight network, then it is likely that such an edge has a small weight but a large $C_{E}^{R F W A}$, which we call the "Crucial Weak Tie". The path of $A \rightarrow C$ is of this type of edge, which is tied for fourth in the weight of edge and second in the $C_{E}^{R F W A}$.

\section{Results}

\subsection{Heterogeneity of pivotability}

It is assumed that the importance of a given park or a technosphere in technology diffusion is determined by the overall performance of enterprises within it, so the research focus can be shifted to the park level or the technosphere level by merging all the patent relationships between enterprises in a certain park or technosphere. To be specific, the merging of the IETTN network is based on the following two rules.

The values in the $C_{E}^{R F W A}$ matrix represent the patent partnership of a node pair and our current goal is to obtain the intensity of cooperation between two parks. In the IETTN model with $M$ parks $(s, r=1,2, \ldots, M)$, the Cross-Park Pivotability Matrix denoted by $P^{C P}$ is:

$$
\begin{gathered}
P^{C P}=\left(\begin{array}{ccc}
P_{11} & \cdots & P_{1 M} \\
\vdots & P_{s t} & \vdots \\
P_{M 1} & \cdots & P_{M M}
\end{array}\right) \\
P_{s t}^{C P}=\sum_{i \in r_{s}} \sum_{j \in r_{t}} C_{E}^{R F W A}(i, j)
\end{gathered}
$$

where $P_{s t}^{C P}$ is the pivotability between park $s$ and park $t, C_{E}^{R F W A}(i, j)$ is that of patent relation between enterprise $i$ and enterprise $j$, and $r_{s}$ and $r_{t}$ are the enterprise set of park $s$ and park $t$ respectively. To observe the heterogeneity of pivotability at the

Journal of Data and Information Science 
Feature and Tendency of Technology Transfer in Z-Park Patent Cooperation Network: From the Perspective of Global Optimal Path

Jun Guan et al.

park-level, park-to-park pivotability matrices of 2008, 2011, 2014, and 2017 have been visualized in the following heat maps (see Figure 8). It should be noted that to show the contrast of the pivotability of parks more obviously, we adopt the logarithmic representation for the results (value of pivotability). The depth of color is proportional to the degree of pivotability while the corresponding value can be found in the legend on the right, and the letters on the left and top axes correspond to Table 1. Specifically, the top 10 pairs of cross-park pivotability of the four years are listed in Table 2.

Table 1. The correspondence between parks, technospheres, and code in motif analysis.

\begin{tabular}{|c|c|c|c|c|c|c|c|}
\hline Park & Code & Park & Code & Technosphere & Code & Technosphere & Code \\
\hline Chaoyang & $\mathrm{CY}$ & Xicheng & $\mathrm{XC}$ & $\begin{array}{l}\text { Electronics and } \\
\text { Information }\end{array}$ & EI & $\begin{array}{c}\text { Marine Engineering } \\
\text { Technology }\end{array}$ & MT \\
\hline Haidian & $\mathrm{HD}$ & Huairou & HR & $\begin{array}{c}\text { Advanced Manufacturing } \\
\text { Technology }\end{array}$ & $\mathrm{AM}$ & $\begin{array}{c}\text { Nuclear Application } \\
\text { Technology }\end{array}$ & NA \\
\hline $\begin{array}{l}\text { Daxing- } \\
\text { Yizhuang }\end{array}$ & DY & Dongcheng & DC & $\begin{array}{l}\text { Bioengineering and New } \\
\text { medicine }\end{array}$ & $\mathrm{BN}$ & Others & OT \\
\hline Miyun & MY & Changping & $\mathrm{CP}$ & $\begin{array}{c}\text { New materials and } \\
\text { Application }\end{array}$ & NM & & \\
\hline Mengtougou & MT & Fangshan & FS & $\begin{array}{l}\text { New Energy and Efficient } \\
\text { Energy-saving Technology }\end{array}$ & $\mathrm{NE}$ & & \\
\hline Shijingshan & SJ & Pinggu & PG & $\begin{array}{c}\text { Modern Agricultural } \\
\text { Techniques and New } \\
\text { Varieties of Plants and } \\
\text { Animals }\end{array}$ & MA & & \\
\hline Tongzhou & $\mathrm{TZ}$ & Shunyi & SY & $\begin{array}{c}\text { Environmental Protection } \\
\text { Technology }\end{array}$ & $\mathrm{EP}$ & & \\
\hline Fengtai & FT & Yanqing & YQ & Aerospace Technology & AT & & \\
\hline
\end{tabular}

Table 2. Top 10 pairs of cross-park pivotability from 2008 to 2017.

\begin{tabular}{|c|c|c|c|c|c|c|c|c|}
\hline \multirow{2}{*}{ Rank } & \multicolumn{2}{|c|}{2008} & \multicolumn{2}{|c|}{2011} & \multicolumn{2}{|c|}{2014} & \multicolumn{2}{|c|}{2017} \\
\hline & Dyad & Num & Dyad & Num & Dyad & Num & Dyad & Num \\
\hline 1 & HD-HD & 558 & HD-HD & 1084 & HD-HD & 1940 & HD-HD & 5136 \\
\hline 2 & CY-CY & 44 & DY-DY & 180 & CY-XC & 1665 & CY-DY & 768 \\
\hline 3 & $\mathrm{XC}-\mathrm{XC}$ & 32 & CY-XC & 157 & CY-DY & 1214 & DY-DY & 442 \\
\hline 4 & FT-FT & 26 & FT-FT & 128 & DY-DY & 332 & FT-FT & 290 \\
\hline 5 & HD-CP & 23 & CY-DY & 96 & FT-FT & 232 & SY-SY & 226 \\
\hline 6 & DY-DY & 16 & CY-CY & 78 & DC-FT & 163 & HD-CP & 204 \\
\hline 7 & SJ-SJ & 14 & $\mathrm{XC}-\mathrm{XC}$ & 54 & CY-CY & 138 & DC-FT & 157 \\
\hline 8 & HD-HR & 11 & DC-FT & 44 & HD-XC & 119 & CY-CY & 102 \\
\hline 9 & HD-FT & 9 & XC-FT & 36 & HD-CP & 98 & HD-XC & 79 \\
\hline 10 & XC-HR & 8 & HD-CP & 33 & $\mathrm{XC}-\mathrm{XC}$ & 60 & CP-CP & 66 \\
\hline
\end{tabular}

It can be seen from the above figure that all parks have witnessed significant changes in their pivotability, especially in the following three aspects:

Journal of Data and Information Science

http://www.jdis.org https://www.degruyter.com/view/j/jdis 


\section{Research Paper}

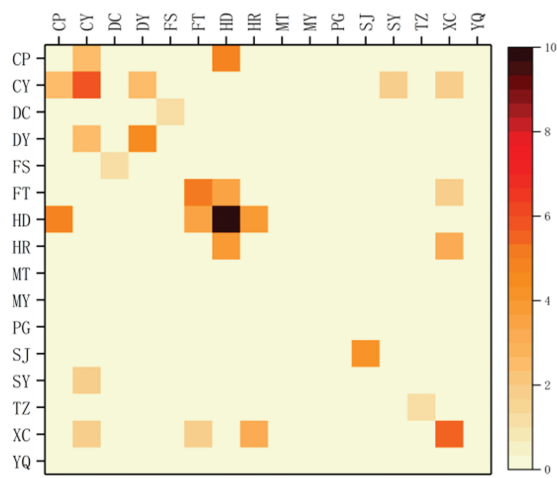

(a) 2008

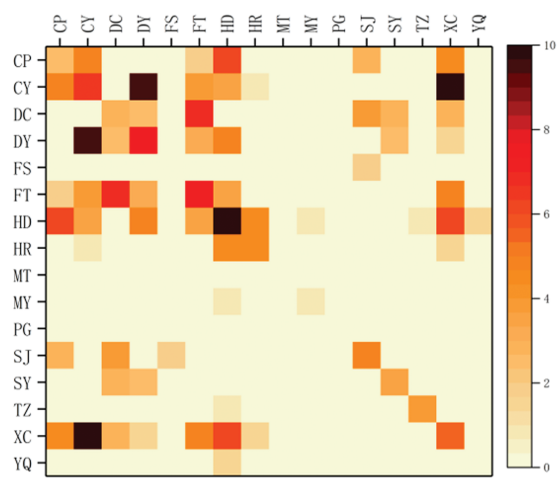

(c) 2014

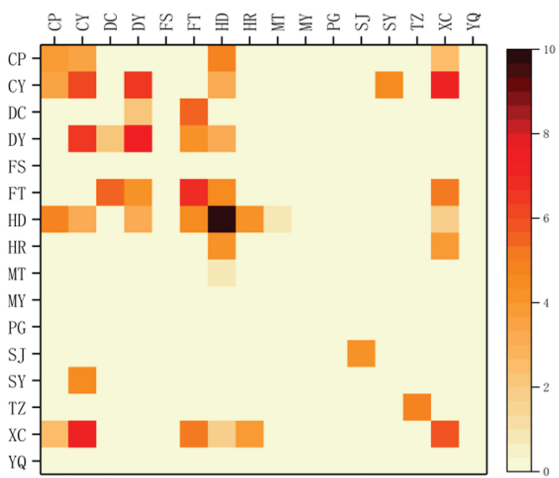

(b) 2011

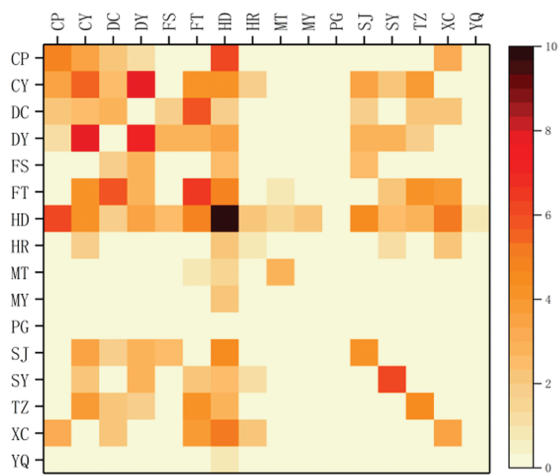

(d) 2017

Figure 8. Cross-park pivotability from 2008 to 2017.

First, the technology-related pivotability in Haidian Park was in a leading position in the four years and showed a significant increase in 2017. The Haidian-Haidian pivotability stood at 558 in 2008, 1084, and 1940 in 2011 and 2014, respectively, and skyrocketed to 5136 in 2017 . Its edge-betweenness-based heterogeneity of pivotability gets increasingly stronger. With the strongest innovation capability among all parks, Haidian Park pools a large number of high-tech enterprises and acts as a perfect source and pivot in innovation diffusion, but the increasing heterogeneity indicates that high-tech enterprises in Haidian Park can hardly facilitate technology diffusion of Z-Park. Its plentiful innovation resources and outstanding innovation capability have not been given full play in the diffusion of technology and resources, and are yet to enhance the innovation capability of Z-Park at large.

Second, the cross-park technology-related pivotability reached its peak in 2014.

Journal of Data and Information Science 
Feature and Tendency of Technology Transfer in Z-Park Patent Cooperation Network:

crawling up. There were more cross-park color blocks in the heat map of 2014. Supported by the policy of comprehensively deepening reform and innovationdriven development, innovation policies and programs are initiated, including the academic system reform, the government's financial support plans, and the launching of intellectual property courts. Scientific and technological achievements and breakthroughs continue to emerge in the fields of high-speed rail, information technology, and aerospace. Despite the economic downturn in 2014, the improved innovation environment and the transformation from scientific researches to productive forces have removed geographical barriers, and continuously integrate resources and technologies across regions, thus enabling vigorous development in scientific and technological innovation.

Third, Yizhuang-Daxing Park, Chaoyang Park, and Xicheng Park account for a large proportion of the cross-park pivotability. Xicheng District is a financial hub of Beijing, and financial technology is one of the leading industries in Xicheng Park. Daxing-Yizhuang Park, relying on the Daxing Bio-medicine Industry Park, has impressive technological accumulation in the field of bioengineering. As for Chaoyang Park, its vital and internationalized cultural background is an attraction for a large number of multinational corporate headquarters, whose gathering has also brought numerous resources for the innovative development of Chaoyang Park. It is noticeable that, in technology diffusion, such parks with distinctive regional characteristics and unique innovative resources play a pivotal role and are more likely to generate a strong attraction in innovation cooperation, thereby facilitating technology transfer and enabling groundbreaking innovation.

Analogously, supposing there are $N$ technical fields $(u, v=1,2, \ldots, N)$ in the IETTN model, the formula of Cross-Technosphere Pivotability Matrix $P^{C F}$ would be:

$$
\begin{gathered}
P^{C T}=\left(\begin{array}{ccc}
P_{11} & \cdots & P_{1 N} \\
\vdots & P_{u v} & \vdots \\
P_{N 1} & \cdots & P_{N N}
\end{array}\right) \\
P_{u v}^{C T}=\sum_{i \in d_{u}} \sum_{j \in d_{v}} C_{E}^{R F W A}(i, j)
\end{gathered}
$$

where $P_{u v}^{C T}$ is the pivotability from technosphere $u$ to technosphere $v$, whose enterprise sets are $d_{u}$ and $d_{v}$, respectively. Accordingly, data of the same years were selected to observe the difference of pivotability at the technosphere-level, as shown in Figure 9. For the same reason shown in Figure 8, the pivotability in Figure 9 is treated logarithmically. The top 10 technosphere pairs by cross-technosphere pivotability in the four years are listed in Table 3.

Journal of Data and Information Science

http://www.jdis.org https://www.degruyter.com/view/j/jdis 


\section{Research Paper}

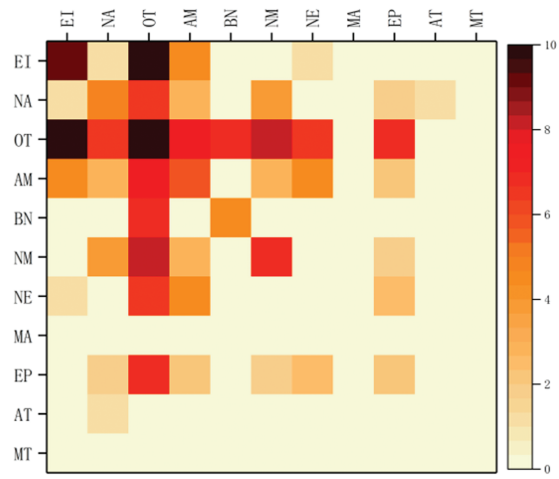

(a) 2008

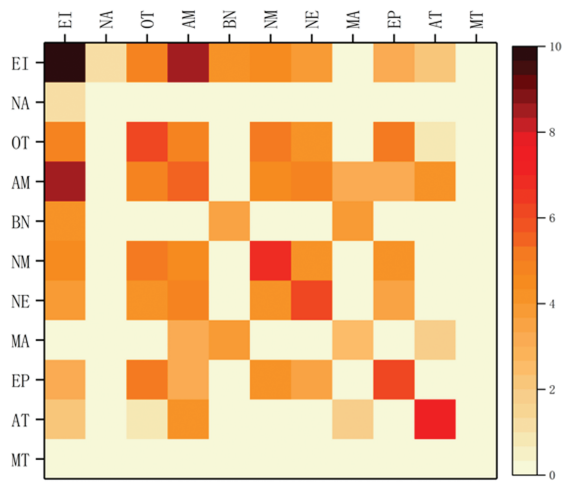

(c) 2014

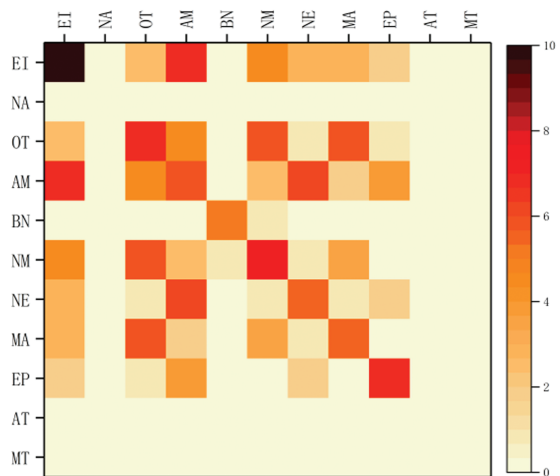

(b) 2011

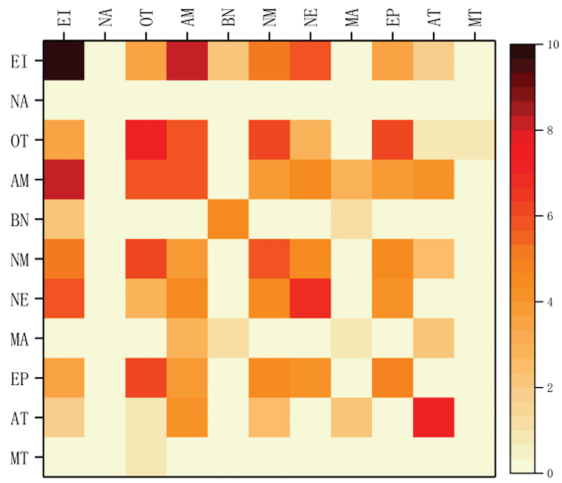

(d) 2017

Figure 9. Cross-technosphere pivotability from 2008 to 2017.

Table 3. Top 10 pairs of cross-technosphere pivotability from 2008 to 2017 .

\begin{tabular}{|c|c|c|c|c|c|c|c|c|}
\hline \multirow{2}{*}{ Rank } & \multicolumn{2}{|c|}{2008} & \multicolumn{2}{|c|}{2011} & \multicolumn{2}{|c|}{2014} & \multicolumn{2}{|c|}{2017} \\
\hline & Dyad & Num & Dyad & Num & Dyad & Num & Dyad & Num \\
\hline 1 & EI-EI & 432 & EI-EI & 1098 & EI-EI & 4598 & EI-EI & 4412 \\
\hline 2 & NM-NM & 86 & NM-NM & 138 & EI-AM & 1259 & EI-AM & 872 \\
\hline 3 & AM-AM & 50 & EI-AM & 122 & AT-AT & 470 & OT-OT & 466 \\
\hline 4 & OT-OT & 24 & OT-OT & 120 & NM-NM & 298 & AT-AT & 448 \\
\hline 5 & BN-MA & 23 & AT-AT & 116 & OT-OT & 192 & NE-NE & 350 \\
\hline 6 & AM-NE & 21 & AM-NE & 76 & NE-NE & 174 & NM-OT & 164 \\
\hline 7 & $\mathrm{BN}-\mathrm{BN}$ & 20 & NM-OT & 58 & EP-EP & 166 & EP-OT & 163 \\
\hline 8 & EI-AM & 19 & EP-OT & 58 & NM-OT & 89 & EI-NE & 150 \\
\hline 9 & NM-OT & 12 & AM-AM & 56 & EP-OT & 69 & AM-AM & 150 \\
\hline 10 & AM-OT & 7 & EP-EP & 50 & AM-OT & 62 & AM-OT & 139 \\
\hline
\end{tabular}

Journal of Data and Information Science
It can be seen from the above figure that the pivotability of each technosphere has changed significantly in the four years, especially in the following two aspects: 
Feature and Tendency of Technology Transfer in Z-Park Patent Cooperation Network:

From the Perspective of Global Optimal Path

Jun Guan et al.

First, the intra-field pivotability in the electronic information field, with the largest proportion, shows a drastic increase in 2011 and 2014, rising from 1,098 in 2011 to 4,598 in 2014. Unquestionably, the electronic information field undergirds innovation development, and with the unstoppable upgrading of computer equipment and Internet applications, the electronic and information field has gained explosive growth in recent years. However, it is worth noting that the fundamental role of the electronic and information field is to facilitate the development of other fields, so limiting the development within its field would be a waste of innovation resources. How to maximize cross-field cooperation is currently a major challenge facing Z-Park.

Second, the science and technology service industry plays an increasingly important role in cross-field cooperation, especially the cooperation with new materials, advanced manufacturing, and environmental protection. In 2014, a policy on accelerating the development of the science and technology service industry was introduced, including science and technology services and supporting technologies into the government-supported high-tech fields and giving preferential tax rates to inject new vitality. It can be seen from the statistics that in recent years, this field has indeed promoted technology diffusion and innovation development of the park. In addition to the necessary innovation provided to support services, the industry has also helped intensify invisible technical exchanges.

\subsection{Park-level pivotablility}

In addition to intra-park collaboration, every park is inextricably linked with others. The pivotability of a given park in the patent cooperation network can be expressed as the overall performance of its patent cooperation with all other parks, based on which we introduce the definition of Park-Level Pivotablility denoted by $P^{R}$ :

$$
P^{R}(s)=\sum P_{s r}^{c p}
$$

where $P^{R}(s)$ is named the park-level pivotability of park $s, P_{s r}$ is the element in the $s$-th row of matrix $P^{C P}$.

Each park has its advantages and disadvantages. The isolation from each other is inconducive to the technology upgrade; it is the openness that truly helps establish a technical cooperation platform and thus intensify cooperation and innovation with advantages of all parties being given full play. In Figure 10, we show the value of the pivotability of 16 parks, in which different colors correspond to different years. The $\mathrm{x}$-coordinate is the park name, and the $\mathrm{y}$-coordinate is the value of pivotability. Therefore, high pivotability means that the park is more active in cooperation, and data of the years 2008, 2011, 2014, and 2017 was selected to observe the pivotal role of each park in patent cooperation.

Journal of Data and Information Science

http://www.jdis.org https://www.degruyter.com/view/j/jdis 


\section{Research Paper}

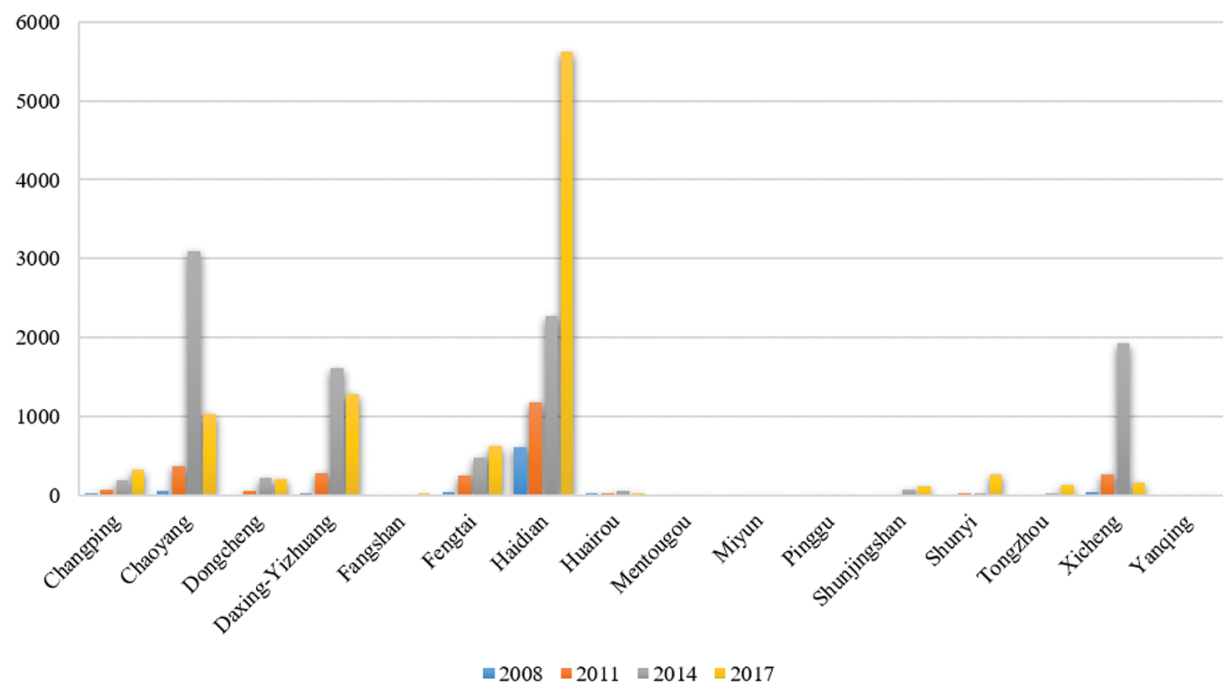

Figure 10. Park-level pivotability from 2008 to 2017.

According to Figure 10, Haidian Park, Chaoyang Park, Yizhuang-Daxing Park, and Xicheng Park boast high Park-Level pivotability. From 2011 to 2014, the pivotability of major parks increased significantly. In particular, Chaoyang Park achieved a leap from 377 to 3,089, surpassing Haidian Park, which has the strongest innovation capability. In 2014, the intra-park pivotability of Chaoyang Park accounted for only $4.5 \%$. As one of the areas with a considerable number of multinational companies and corporate headquarters, Chaoyang Park has always been in a leading position in cooperation across regions and even countries and has a distinctive innovation specialty of international $R \& D$, attracting more than 150 multinational companies from more than ten countries and regions to invest and settle in. The introduction of international innovation resources, despite the barriers in the development of core technologies, has hugely attracted and expanded regional and cross-regional cooperation. The pivotability of Xicheng Park also increased from 272 in 2011 to 1,927 in 2014. Xicheng Park is committed to establishing a demonstration zone for innovation in financial technology and specialized services, which promote and facilitate the innovative development of the entire park. The promotion of specialized service parks is also prominently beneficial to technology diffusion.

As always, Haidian Park tops all the other parks in terms of pivotability. Especially in 2017, significantly enhanced on the original basis, the pivotability of Haidian Park reached 5,626, in which, however, the intra-park pivotability is as high as $91 \%$.

Journal of Data and With a large number of scientific research institutes and high-tech enterprises, the Information Science basic innovation strength of Haidian Park is undoubted, especially in the field of 
Feature and Tendency of Technology Transfer in Z-Park Patent Cooperation Network:

From the Perspective of Global Optimal Path

Jun Guan et al.

electronics and information. Its early start and profound basic innovation strength led to high industry and geographic agglomeration, and on the other hand, limited its communication and cooperation with other parks. Considering its unquestionably high innovation output, it does not play a matching role in technical cooperation and innovation diffusion.

\subsection{Technosphere-level pivotability}

Accordingly, we defined the technosphere-level pivotability by summarizing the patent partnerships between a technology field and all others, i.e. summing up the elements in each row of the matrix $P^{C T}$ respectively to thus get the vector $P^{D}$ :

$$
P^{D}(u)=\sum P_{u v}^{C T}
$$

where $P^{D}(u)$ is named the technosphere-level pivotability of technosphere $u$, and $P_{u v}$ represents the elements in the $u$-th row of matrix $P^{C T}$.

The following figure shows the degree of pivotability in the different technosphere. Similarly, different colors represent different years. It should be noted that because the degree of technosphere in the field of electronics and information is much higher than in other fields, we add a double line to the vertical axis to compress to show all the values clearly. Cooperation across technospheres is an effective way to expand cooperation, which is often accompanied by the emergence of new products, new technologies, and new design concepts. Then the variation of technospherelevel pivotability at different times is analyzed to explore the dynamic influence of different technology fields in the patent cooperation network.

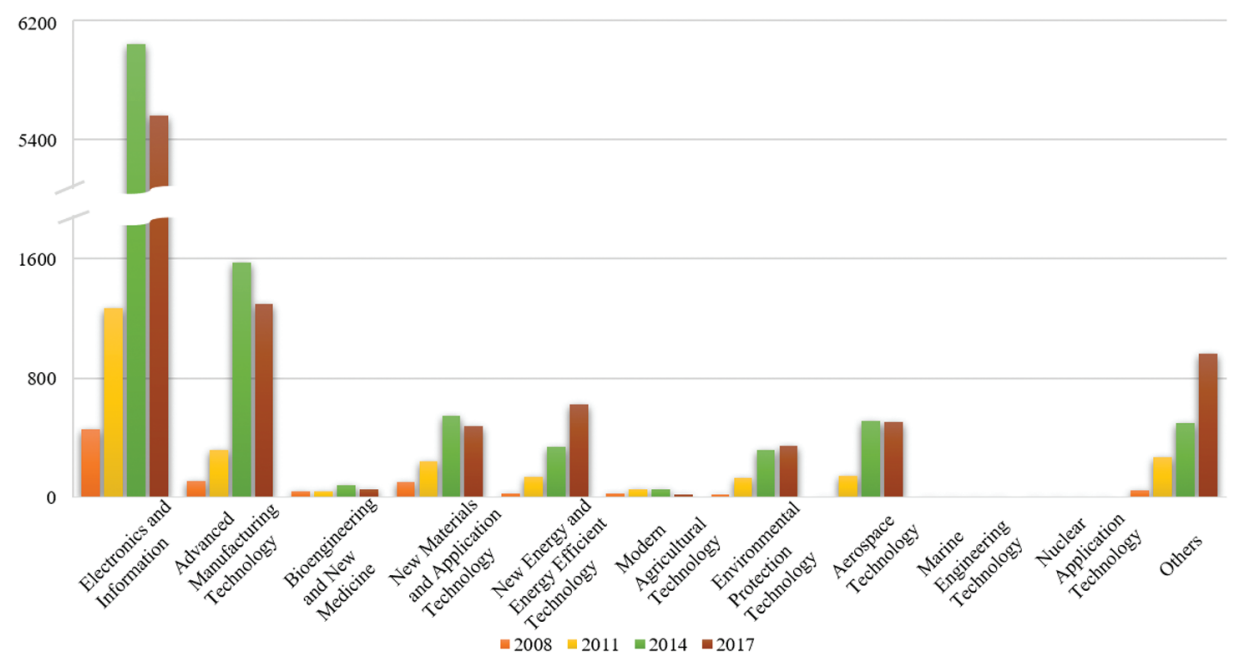

Figure 11. Technosphere-level pivotability from 2008 to 2017.

Journal of Data and Information Science

http://www.jdis.org https://www.degruyter.com/view/j/jdis 


\section{Research Paper}

According to Figure 11, the electronic and information field boasts high technosphere-level pivotability, exceeding 6,040 in 2014. It continuously contributes to innovative development with its considerable high-tech enterprises and the most extensive regional distribution. Between 2014 and 2015, the concept of "Internet +" gave rise to the emerging development pattern of deep integration of the Internet and traditional industries, which led to the technology diffusion in the electronic and information field and the upgrade of traditional industries. At the same time, the "Made in China 2025" Strategy emphasizes the integrated development of manufacturing industries and the Internet, making advanced manufacturing technology a hub area for close collaboration and exchanges with the electronic information field. Seen from a dialectical point of view, the innovation in this field still focuses more on the innovation of the business model, rather than technological innovation concerning people's livelihood and national hard power. Therefore, to enhance the overall innovation strength of a region, enterprises in the field need to break individual and industrial restrictions, establish extensive and in-depth cooperation with enterprises in other fields, and play a pivotal role, with more focus on technologies regarding $5 \mathrm{G}$ and aerospace.

As can be seen from the above figure, although the pivotability of major technosphere in 2017 has slightly decreased compared with 2014, and an increase has been seen in the pivotability of new energy and high-efficiency energy-saving technology and environmental protection technology, among which that of the new energy technosphere rose from 342 to 626 . At the end of 2016, the 13th "Five-Year Plan" for energy development emphasized technological innovation in the energy field and clean and low-carbon development, which provided new impetus for cooperative innovation and technological updates. Since both national strategies and public awareness have higher requirements for environmental protection and lowcarbon life, the environmental protection industry is expected to have more and more in-depth cooperation with other fields.

\section{Discussion and conclusions}

Recently, related researches mainly adopt the following paradigm. Some take regional and technosphere factors as external environment variables; some use econometrics to incorporate those factors into model variables, and then establish a relationship with innovation performance; others observe the agglomeration phenomenon within the region or technical field through cluster analysis. Based on the first principle of physics, our research reviews the nature of the effect of region and technosphere on innovation and restoring the role of the region or technosphere to be taken as the basis for quantitative analysis. The complex network model is 
Feature and Tendency of Technology Transfer in Z-Park Patent Cooperation Network:

applied to examine the cooperation relationship of the system, and thus a causal relationship is established in both micro and macro sense between innovation network topological structure and development trend.

The above analysis shows that technical cooperation has guided the formation and improvement of the entire network. More and more parks are participating in technical cooperation, together contributing to the fully-developed Z-Park innovation collaboration network. The overall density of the Z-Park technology collaboration network is relatively high, but it also displays conspicuous scale-free characteristics. Some nodes in the network have numerous network edges, and some are unevenly distributed. Among all parks, Haidian Park boasts the most considerable intra-park and cross-park technical cooperation, especially in the initial stage of the Z-Park innovation network formation. And those parks with distinctive industrial advantages boast rich cooperation opportunities: for instance, Daxing-Yizhuang Park has profound technological accumulation in the bioengineering and pharmaceutical industry, and Xicheng Park enjoys a highly developed and vigorous fintech industry. In technospheres, electronics, and information, advanced manufacturing are key areas of technical cooperation in Z-Park. They have forged extensive technical cooperation relationships with other technical fields and have led the technology transfer collaboration network. However, the existing cooperation in the electronic and information field is still limited to intra-technosphere cooperation, with more focus on the innovation in the business model, instead of fully unlocking its potentials in general innovation and the upgrading of traditional industries. In conclusion, the impact of the technospheres on technology diffusion is determined by national strategies, policy support, and characteristics of different industries.

Based on the above analysis of the existing structure of the patent cooperation network, it is not difficult to find that behind the phenomenon of influence of parks and technospheres on the technology transfer, there are deeper influencing factors, such as the history of development, industrial characteristics, policy support, social focus and so on. As one of the earliest parks in Z-Park, Haidian Park has accumulated abundant innovation resources and attracted powerful innovation subjects, which is one of the reasons why it has become the most attractive park in the network. The park's support policies for specific fields will lead to the agglomeration of enterprises in the same field and improve the competitiveness of the park in the cooperation network. Industrial characteristics will also affect the cooperation between enterprises. For example, the high technical requirements in the aerospace industry, to some extent, restrict its innovation cooperation with other fields. Besides, technology hotspots of high social concern such as the "Internet + " and "Made in China 2025" have brought the industrial integration of these fields and enhanced the pivotal role of specific technospheres in technological cooperation. Given the COVID-19 outbreak in 2020, it is reasonable to believe that enterprises in the field

Journal of Data and Information Science

http://www.jdis.org https://www.degruyter.com/view/j/jdis 


\section{Research Paper}

of bioengineering and new medicine will have a more prominent impact on technical cooperation in the next few years.

There are inevitably some defects in our analysis. Due to data limitations, only the joint patent applications are taken into account for establishing the patent cooperation network without considering the various forms of patent partnership among enterprises. Besides, inter-enterprise innovation cooperation involves not merely patent cooperation but also factors regarding their innovation correlation, such as product circulation and capital exchanges, so further research is needed to fill the gap. The gap between the number of innovative enterprises and innovative output in the parks and technospheres is shown in the results but not concretely quantified. Future research is expected to consider these elements.

\section{Acknowledgments}

This work was support by the National Natural Science Foundation of China (Grant No. 71971006), Beijing Natural Science Foundation (Grant No. 9194024), Technology Plan Key Program of Beijing Municipal Education Commission (Grant No. KZ20181005010).

\section{Author contributions}

Jun Guan (guanjun@bjut.edu.cn): Supervision, Funding acquisition. Jingying Xu (xjy19961114@163.com): Writing-Original draft, Visualization. Yu Han (17864192095@163.com): Investigation. Dawei Wang (wdw0116@163.com): Data Curation, Software. Lizhi Xing (itwasa@163.com): Funding acquisition, writing-reviewing \& editing.

\section{References}

Burt, R.S. (1983). Corporate profits and cooptation: Network of market constraints and directorate ties in the American economy. New York: Academic Press.

Chai, K.C., Yang, Y., Sui, Z.Y., \& Chang, K.C. (2010). Determinants of highly-cited green patents: The perspective of network characteristics. PLOS ONE, 15(10), e0240679.

Chen, J., Wu, H., \& Liu, W.L. (2014). Zhongguancun: Future world's first innovation cluster. Studies of Science in Science, 32(1), 5-13.

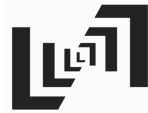

Journal of Data and Information Science
Cong, H.B., Zou, D.L., \& Wu, F.X. (2017). Influence mechanism of multi-network embeddedness to enterprises innovation performance based on knowledge management perspective. Cluster Computing-The Journal of Networks Software Tools and Applications, 20(1), 93-108.

DeBresson, C., \& Amesse, F. (1991). Networks of innovators: A review and introduction to the issue. Research Policy, 20(5), 363-379.

Drucker, P.F. (1985). Innovation and entrepreneurship: Practice and principles. New York: Harper Business.

Fang, G., Zhou, Q., Wu, J., \& Qi, X.G. (2019). The relationship between network capabilities and innovation performance: Evidence from Chinese high-tech industry. Industrial Management \& Data Systems, 119(8), 1638-1654. 
Feature and Tendency of Technology Transfer in Z-Park Patent Cooperation Network: From the Perspective of Global Optimal Path

Foss, N.J., Lyngsie, J., \& Zahra, S.A. (2013). The role of external knowledge sources and organizational design in the process of opportunity exploitation. Strategic Management Journal, 34(12), 1453-1471.

Freeman, C. (1987). Technology policy and economic performance: Lessons from Japan. London: Pinter Publisher.

Freeman, C. (1995). The 'National System of Innovation' in historical perspective. Cambridge Journal of Economics, 19(1), 5-24.

Freeman, C. (1991). Networks of innovators: A synthesis of research issues. Research Policy, 20(5), 499-514.

Girvan, M., \& Newman, M.E.J. (2002). Community structure in social and biological networks. Proceedings of the National Academy of Sciences of the United States of America, 99(12), 7821-7826.

Granovetter, M.S. (1973). The strength of weak ties. American Journal of Sociology, 78(6), 13601380.

Hienerth, C., Lettl, C., \& Keinz, P. (2014). Synergies among producer firms, lead users, and user communities: The case of the LEGO producer-user ecosystem. Journal of Product Innovation Management, 31(4), 848-866.

Hua, L., \& Wang, W.P. (2015). The impact of network structure on innovation efficiency: An agent-based study in the context of innovation networks. Complexity, 21(2), 111-122.

Hung, S.W., \& Wang, A.P. (2010). Examining the small world phenomenon in the patent citation network: A case study of the radio frequency identification (RFID) network. Scientometrics, 82(1), 121-134.

Jiang, H.J., Liu, Y., Hou, Y.Y., \& Liu, W.L. (2016). An evaluation of the contribution of Zhongguancun to Beijing's economic and social development. Science Research Management, 37, 591-601.

Laranja, M., Uyarra, E., \& Flanagan, K. (2008). Policies for science, technology and innovation: Translating rationales into regional policies in a multi-level setting. Research Policy, 37(5), 823-835.

Lee, S., Park, G., \& Yoon, B. (2010). Open Innovation in SMEs-An Intermediated Network Model. Research Policy, 39(2), 290-300.

Lin, L., Xu, J.Y., Xing, L.Z., \& Guan, J. (2020). Analysis on the topological structure of InterEnterprise technology transfer network: Taking Z-Park as an example. International Journal of Modern Physics B, 2050131.

Liu, F.C., Zhang, N., \& Cao, C. (2017). An evolutionary process of global nanotechnology collaboration: A social network analysis of patents at USPTO. Scientometrics, 111(3), 14491465.

Lu, C., Yu, B., Liu, L.N., \& Zhang, J. (2019). Impacts of formal/informal collaboration networks on innovation performance of SMEs. R\&D Management, 31(6), 24-36.

Lundvall, B.A. (1992). National system of innovation: Towards a theory of innovation and interaction learning. London: Pinter Publisher.

Mao, C.F., Yu, X.Y., Zhou, Q., Harms, R., \& Fang, G. (2020). Knowledge growth in universityindustry innovation networks - Results from a simulation study. Technological Forecasting and Social Change, 151(2020), 119746.

Journal of Data and Information Science

http://www.jdis.org https://www.degruyter.com/view/j/jdis 


\section{Research Paper}

Maroulis, S. (2017). The role of social network structure in street-level innovation. American Review of Public Administration, 2017, 47(4), 419-430.

Musiolik, J., Markard, J., \& Hekkert, M. (2012). Networks and network resources in technological innovation systems: Towards a conceptual framework for system building. Technological Forecasting and Social Change, 79(6), 1032-1048.

Rampersad, G., Quester, P., \& Troshani, I. (2010). Managing innovation networks: Exploratory evidence from ICT, biotechnology and nanotechnology networks. Industrial Marketing Management, 39(5), 793-805.

Rosalba, C., Rebeca, D.G., \& Josefa, S.M. (2000). The building of knowledge spaces in Mexico: A regional approach to networking. Research Policy, 29(2), 225-241.

Schumpeter, J.A. (1911). Theory of economic development. Cambridge: Harvard University Press.

Shi, X.X., \& Zhang, Q.P. (2020). Network inertia and inbound open innovation: Is there a bidirectional relationship? Scientometrics, 122, 791-815.

Stephen, P.B., Ajay, M., Daniel, J.B., \& Giuseppe, L. (2009). Network analysis in the social sciences. Science, 323(5916), 892-895.

Sternberg, R., \& Arndt, O. (2000). The firm or the region: What determines the innovation behavior of European firms? Economic Geography, 77, 365-382.

Tang, F.C., Ma, J., \& Xi, Y.M. (2004). The coupling mechanism and emergence of Hexie management. Systems Engineering-Theory \& Practice, 11, 68-75.

Tian, L., Di, Z.R., \& Yao, H. (2011). The influence of weight distribution on the efficiency of weighted network. Acta Physica Sinica, 2, 807-812.

Tzeng, C. (2010). Managing innovation for economic development in greater China: The origins of Hsinchu and Zhongguancun. Technology in Society, 32(2), 110-121.

Wei, S.T., Zhang, Z., Ke, G.Y., \& Chen, X.T. (2019). The more cooperation, the better? Optimizing enterprise cooperative strategy in collaborative innovation networks. Physica A: Statistical Mechanics \& Its Applications, 534, 120810.

Wu, J.S., \& Di, Z.R. (2004). Complex networks in statistical physics. Process in Physics, 24(1), $18-46$.

Xing, L.Z., Dong, X.L., Guan, J., \& Qiao, X.Y. (2019). Betweenness centrality for similarityweight network and its application to measuring industrial sectors' pivotability on the global value chain. Physica A: Statal Mechanics and its Applications, 516, 19-36.

Yoon, J., \& Kim, K. (2012). An analysis of property-function based patent networks for strategic R\&D planning in fast-moving industries: The case of silicon-based thin film solar cells. Expert Systems with Applications, 39(9), 7709-7717.

Zhou, L.J. (2010). Research on the system structure and innovation capability of regional innovation network. Science and Technology Management Research, 2, 10-12.

Zhou, Y.H., Zhang, Z.G., \& Liu, K.J. (2004). A study on the motive mechanism of knowledge management in the process of enterprise technological innovation. R\&D Management, 16(6), $9-14$.

\section{(9) $\odot \Theta \Theta$}

Journal of Data and This is an open access article licensed under the Creative Commons Attribution-NonCommercialInformation Science 
Feature and Tendency of Technology Transfer in Z-Park Patent Cooperation Network:

Jun Guan et al. From the Perspective of Global Optimal Path

\section{Appendix}

Table 4. Specific classification of 11 technospheres.

\begin{tabular}{|c|c|}
\hline Technosphere & Segmentation \\
\hline Electronics and information & $\begin{array}{l}\text { Computer and related products } \\
\text { Computer peripherals } \\
\text { Information processing equipment } \\
\text { Computer network equipment and products } \\
\text { Computer software } \\
\text { Microelectronics and electronic components } \\
\text { Broadcast television equipment } \\
\text { Communication device } \\
\text { Artificial intelligence products }\end{array}$ \\
\hline $\begin{array}{l}\text { Bioengineering and the new } \\
\text { medicine }\end{array}$ & $\begin{array}{l}\text { Biotechnology and products } \\
\text { Traditional Chinese medicine } \\
\text { Pharmaceutical chemicals } \\
\text { Agricultural biotechnology } \\
\text { Environmental engineering } \\
\text { Bio-safety } \\
\text { Biomedical engineering }\end{array}$ \\
\hline $\begin{array}{l}\text { Advanced manufacturing } \\
\text { technology }\end{array}$ & $\begin{array}{l}\text { Advanced manufacturing equipment } \\
\text { Medical apparatus and instruments } \\
\text { Robot } \\
\text { Electromechanical basic part } \\
\text { Instruments and apparatus } \\
\text { Monitoring equipment and control system } \\
\text { Optoelectronic components and their products }\end{array}$ \\
\hline New materials and application & $\begin{array}{l}\text { Metallic material } \\
\text { Ceramic Materials } \\
\text { Organic polymer materials }\end{array}$ \\
\hline Aerospace technology & $\begin{array}{l}\text { Aircraft and supporting products } \\
\text { Aeronautical ground equipment } \\
\text { Carrier rocket } \\
\text { Spacecraft } \\
\text { Other special rockets and detection rockets }\end{array}$ \\
\hline $\begin{array}{l}\text { Modern agricultural techniques } \\
\text { and new varieties of plants and } \\
\text { animals }\end{array}$ & $\begin{array}{l}\text { Products of embryos and fine-breed of herbivorous livestock } \\
\text { Biological pesticides and biological control products } \\
\text { New diagnostic reagents and veterinary vaccines } \\
\text { New high-efficiency feed and additive } \\
\text { The new type of fertilizer } \\
\text { Facility agricultural engineering and equipment } \\
\text { New technology and equipment for processing agricultural products } \\
\text { New testing technology and equipment for agricultural products } \\
\text { Agricultural information technology and related products }\end{array}$ \\
\hline $\begin{array}{l}\text { New energy and efficient } \\
\text { energy-saving technology }\end{array}$ & $\begin{array}{l}\text { New energy } \\
\text { Efficient energy-saving technology }\end{array}$ \\
\hline
\end{tabular}

Journal of Data and Information Science 


\section{Research Paper}

\begin{tabular}{ll}
\hline \multicolumn{1}{c}{ Technosphere } & \multicolumn{1}{c}{ Segmentation } \\
\hline Environmental protection & Air pollution prevention equipment \\
technology & Water pollution prevention equipment \\
The new type of solid waste treatment equipment & New technology and equipment of noise vibration, electromagnetic \\
& radiation, and radioactive pollution prevention and control system \\
& Advanced environmental monitoring equipment \\
& New materials and pharmaceutical products for environmental protection \\
& Technology and equipment for environmental protection and restoration \\
& New and efficient clean energy application technologies \\
\hline Marine engineering technology & Marine monitoring instrument \\
& Marine telemetry technology and equipment \\
& Hydro-acoustic communication technology and equipment \\
& Submarine seismic observation technology and equipment \\
\hline Nuclear application technology & Nuclear radiation product \\
& Radiation-processed products \\
& Isotopes and their applications \\
& Nuclear material \\
Accelerator and supporting Equipment \\
Nuclear detectors and nuclear electronics \\
Equipment for nuclear physics and chemistry experiments \\
Nuclear medicine diagnostic and therapeutic instruments and equipment \\
Nuclear reactors and associated installations \\
Technology and equipment for the treatment of radioactive wastes
\end{tabular}

Related technical products supporting the above ten fields, and suitable for the capital's economic development

Journal of Data and Information Science 